\title{
Research on Application Technology of Self Melting Ice Fine Surface Treatment
}

\author{
Bingjian LIU ${ }^{\mathrm{a}}$, Shujie WANG ${ }^{\mathrm{b}, 1}$, Xin $\mathrm{HU}^{\mathrm{c}}$, Qiancheng MA ${ }^{\mathrm{b}}$, Hao $\mathrm{YU}^{\mathrm{b}}$ and Xiangyan \\ $\mathrm{WU}^{\mathrm{c}}$ \\ ${ }^{a}$ Chifeng Jingpeng Daban Expressway Construction Management Office, Inner \\ Mongolia Autonomous Region Chifeng, 02400, China \\ ${ }^{\mathrm{b}}$ China Academy of Transportation Sciences, Beijing Chaoyang, 100029, China \\ ${ }^{c}$ Chongqing Chengbang Pavement Material Co., Ltd, Chongqing Nanan, 401336, \\ China
}

\begin{abstract}
The construction of the expressway network has brought great convenience to the people's travel, and it also brings the hidden danger of driving safety, especially the snow and ice problem in winter which threatens the safety of the people's life and property. In order to solve the problem of dark(black)ice on the pavement safely, quickly, efficiently and conveniently, this study has developed a self melting ice fine surface treatment technology with the combination of the preventive maintenance mask technology and the self melting ice technology, which will have a definite effect on the deicing technology of the highway pavement in winter.
\end{abstract}

Keywords. Fine surface treatment, preventive maintenance, self melting ice modifier, snow and ice

\section{Introduction}

Fine surface treatment is a thin layer technology for fine surface treatment of asphalt pavement [1]. As shown in figure 1. Fine surface treatment material is a kind of conditioning and curing material for asphalt pavement. The fine surface treatment material is a multi-component normal temperature reactive epoxy modified asphalt binder. It is mainly used that the molecular chain of refined asphalt material and epoxy resin has reaction groups. During molding, the molecular chain is cross-linked through the action of its own reaction groups, so that the system changes from linear structure to body structure. It has excellent penetration, aging resistance, high adhesion and high durability. After being sprayed on the pavement by mechanical force, it will quickly penetrate below the road surface, adsorb on the pavement tissue it contacts, and repair the surface aging tissue through cross-linking reaction, so as to re bond the loose aggregate and close the micro cracks on the surface of the pavement, which can effectively resist the erosion of organic solvents and chemicals. The fine surface is specially used for preventive maintenance of asphalt pavement.

\footnotetext{
${ }^{1}$ Shujie Wang, China Academy of Transportation Sciences, Beijing Chaoyang, 100029, China; E-mail: 836884922@qq.com.
} 
In winter, the snow and ice on the asphalt pavement not only lead to traffic accidents, but also greatly reduce the efficiency of road transport [2-5]. More snowmelting materials and technologies have been developed to solve this problem around the world. The existing new technologies for snow melting and ice melting of asphalt pavement are salt storage asphalt mixture and self-deicing coating [6-10]. There is no self melting fine surface treatment technology for asphalt pavement pre-curing technology. It is essential to develop new self melting fine surface treatment technology which is with both self melting and preventive maintenance functions[11].

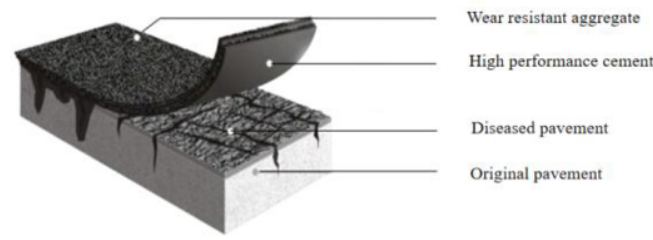

Figure 1. Schematic diagram of fine surface pavement.

\section{Development of Self Melting Ice Modifier}

\subsection{Experimental Steps}

Prepare high-performance binder for wrapping self melting ice modifier, accurately weigh the self melting ice modifier material to be wrapped, pour it into the mixing pot and stir evenly.

After discharging, it shall be placed at room temperature for $6 \mathrm{~h}$ until it is completely cured, sealed and stored for use.

\subsection{Experimental Results of Self Melting Ice Modifier}

Different kinds, types and self melting ice modifiers from different manufacturers are selected for surface treatment. The test shall be carried out according to the principle of single variable to verify that different surface treatment materials, oil consumption of different surface treatment materials and different surface treatment methods are used for verification. As shown in figures 2 and 3.
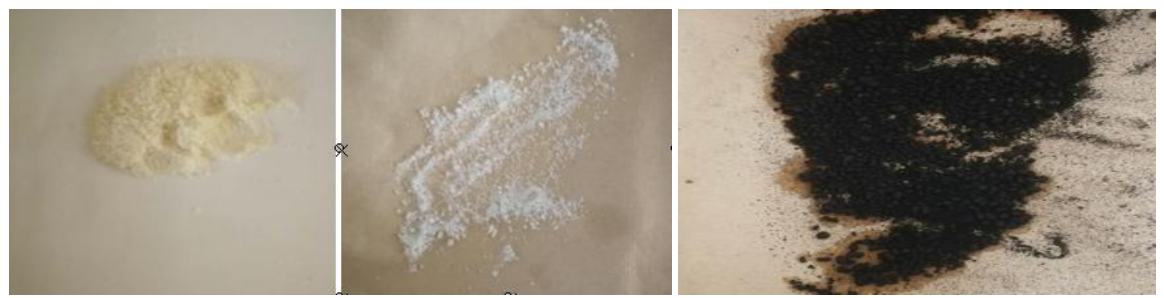

Figure 2. Type I self melting ice modifier. 

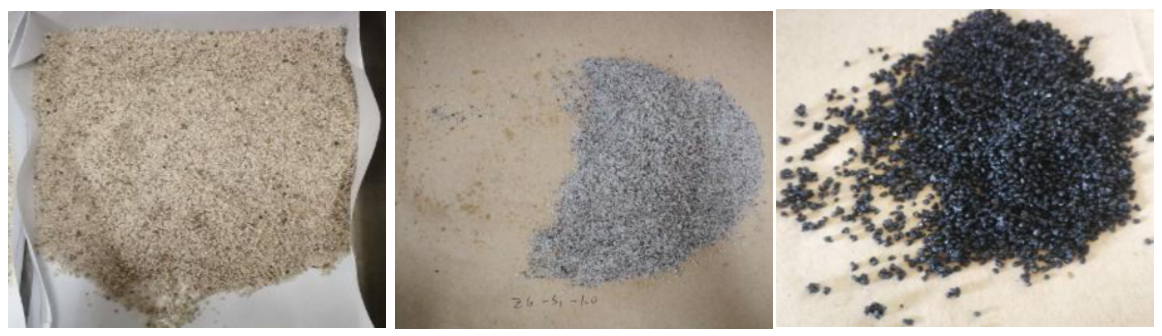

Figure 3. Type II self melting ice modifier.

Type I self melting ice modifier has serious moisture absorption, and the increased surface treatment still has serious moisture absorption, which affects the later use effect and cannot be used. Type II self melting ice modifier basically does not absorb moisture and can be used after wrapping surface treatment.

\section{Self Melting Ice Fine Surface Preparation}

\subsection{Mixing Mode Experiment}

According to the previous experiments, type II self melting ice modifier is selected and applied to the fine surface after surface treatment. The modifier is verified and added to the first layer of fine surface aggregate and the second layer of fine surface aggregate respectively. As shown in figure 4. The experimental conditions are as follows:
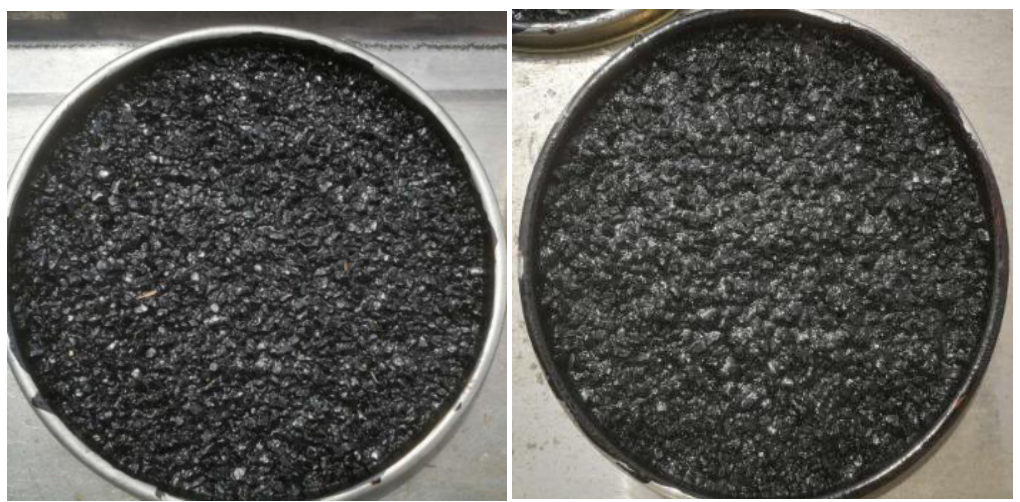

Figure 4. Specimen at fine surface of self melting ice (The left figure is added to the first floor and the right figure is added to the second floor).

The self melting ice modifier is applied to the second layer of fine surface treatment. Due to the emulsified asphalt used in the second and third layers, the self melting ice modifier of the second layer will directly contact with the water in the emulsified asphalt of the second and third layers, resulting in the rapid release of the anticoagulant in a short time and affecting the forming of the second and third layers.

The self melting ice modifier is applied to the first layer of fine surface. This situation will not affect the curing and strength of the high-performance binder at the bottom layer, and has the least impact on the second layer. When the humidity is lower 
than $65 \%$, the second fine surface can be completely demulsified and formed without affecting the curing of the third fine surface. Finally, it is confirmed that the anticoagulant is added to the first layer to replace some aggregates.

\subsection{Mixing Amount Experiment}

\subsubsection{Fabrication of Test Piece}

According to the preliminary test, the self melting ice modifier with surface treatment is selected and mixed in the first layer. We use different amounts of self melting ice modifier to spread in the first layer of fine surface. After the first layer is formed, we make the second and third layers according to the fine surface process, and track the formation of each layer of fine surface. As shown in figure 5.
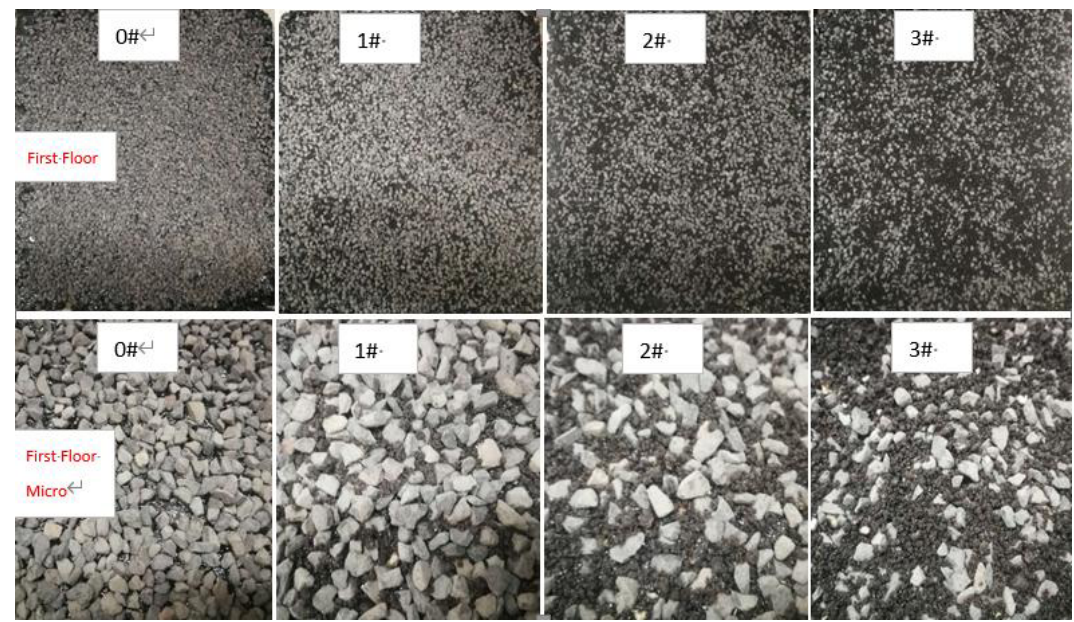

Figure 5. Forming of the first layer (From left to right, the self melting ice modifier increased in turn).

0\# only $3.5 \mathrm{~kg} / \mathrm{m}^{2}$ of $2-4 \mathrm{~mm}$ basalt is distributed, and there is basically no accumulation of stones, with a small amount of voids.

1 \# distribute $3.5 \mathrm{~kg} / \mathrm{m}^{2}$ of $2-4 \mathrm{~mm}$ basalt and $0.35 \mathrm{~kg} / \mathrm{m}^{2}$ of self melting ice modifier. There is basically no accumulation of stones. The gaps between stones are basically filled with self melting ice modifier, and the self melting ice modifier is not accumulated on the surface of stones.

$2 \# 3.0 \mathrm{~kg} / \mathrm{m}^{2}$ of $2-4 \mathrm{~mm}$ basalt and $0.7 \mathrm{~kg} / \mathrm{m}^{2}$ of self melting ice modifier are distributed, which reduces the amount of stone materials, and there is no accumulation between stones, but the anticoagulant ice modifier completely fills the gap, and some self melting ice modifiers are accumulated on the surface of stones.

$3 \# 3.0 \mathrm{~kg} / \mathrm{m}^{2}$ of $2-4 \mathrm{~mm}$ basalt and $1.0 \mathrm{~kg} / \mathrm{m}^{2}$ of fine anticoagulant ice agent are distributed to reduce the amount of stones. There is no accumulation between stones, but the anticoagulant ice agent completely fills the gap, and most of the anticoagulant ice agent is accumulated on the surface of stones, covering most of the surface stones. 

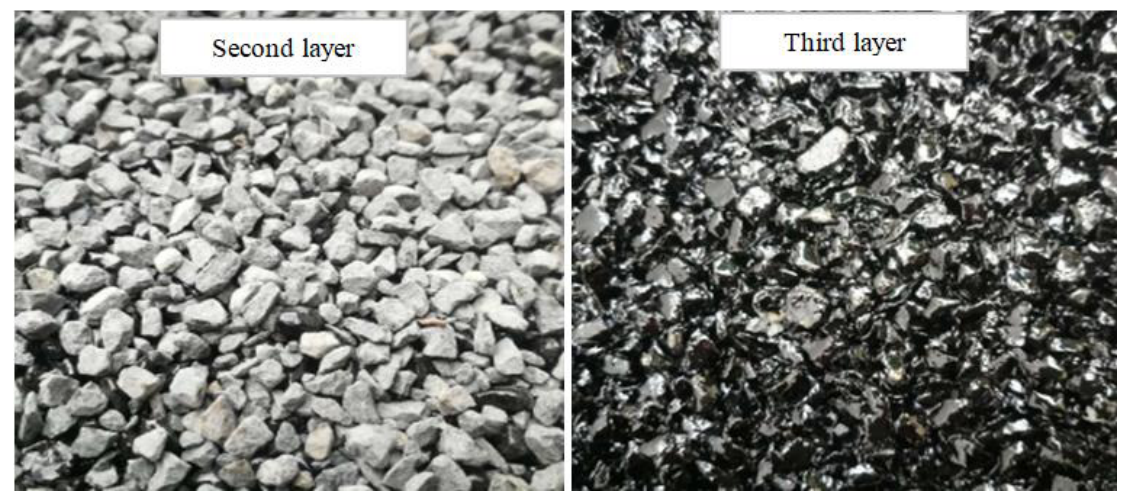

Figure 6. Forming of the second and third layers.

As shown in figure 6 . The second layer of test plate shall be manufactured by spraying device and placed in the sun for curing. Type II cementitious material is normally demulsified. The stone does not absorb moisture, and the apparent adhesion has not been significantly affected. The third layer is made after curing for $4 \mathrm{~h}$.

The third layer of test panels are made without abnormality. They are sprayed with type II cement according to the proportion and placed in the sun for curing. There is no moisture absorption during the curing process. The type II cement is normally demulsified. The stone does not absorb moisture, and the apparent adhesion has not been significantly affected.

\subsubsection{Testing of Bond Strength}

The pull-out specimens were prepared on the above four test plates with different amounts of self melting ice modifier. They were firmly bonded with epoxy adhesive, cured at room temperature for $6 \mathrm{~h}$, and completely cured. We use a cutting machine to cut the specimen, and then use a bond strength tester to test the drawing strength. As shown in figure 7 .
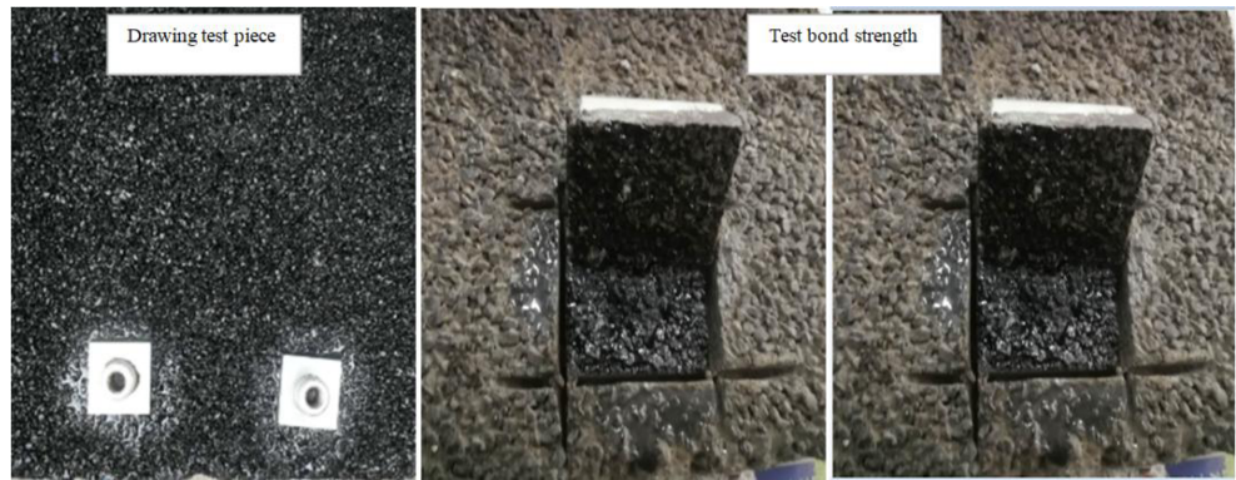

Figure 7. Bond strength test. 
Table 1. Test data of bond strength.

\begin{tabular}{llll}
\hline Serial number & \multicolumn{2}{l}{ Bond strength $(\mathrm{MPa})$} & Mean value $(\mathrm{MPa})$ \\
\hline $0 \#(0)$ & 0.189 & 0.236 & 0.213 \\
$1 \#\left(0.35 \mathrm{~kg} / \mathrm{m}^{2}\right)$ & 0.182 & 0.171 & 0.177 \\
$2 \#\left(0.7 \mathrm{~kg} / \mathrm{m}^{2}\right)$ & 0.146 & 0.138 & 0.142 \\
$3 \#\left(1.0 \mathrm{~kg} / \mathrm{m}^{2}\right)$ & 0.112 & 0.124 & 0.118 \\
\hline
\end{tabular}

According to the bond strength test data in table 1, it can be seen that the test interruption layer is the second layer of type II cement. With the increase of the amount of self melting modifier, the bond strength decreases, indicating that the self melting modifier has a certain effect on the type II binder layer.

Therefore, the addition amount of self melting ice modifier in the fine surface is $0.5 \mathrm{~kg} / \mathrm{m}^{2}$ to ensure the self melting performance and minimize the impact on the fine surface.

\section{Study on Self Melting Ice Performance}

\subsection{Experimental Process}

Spread $150 \mathrm{~g}$ of water on the surface of $0 \#$ and $1 \#$ test pieces respectively. After $30 \mathrm{~min}$, place the drawing test piece on the surface of the test piece so that the water surface is in full contact with the drawing test piece.

Open the low-temperature test chamber to $-10^{\circ} \mathrm{C}$ until it is stable. Place the above test pieces in a low-temperature oven for $2 \mathrm{~h}$, and track the surface water freezing of the test pieces.

Test the bond strength of ice layer with a pullout instrument, and record and take photos. Cut the ice surface with a knife and track the freezing of the ice layer and the bottom specimen.

\subsection{Process Tracking and Result Discussion}
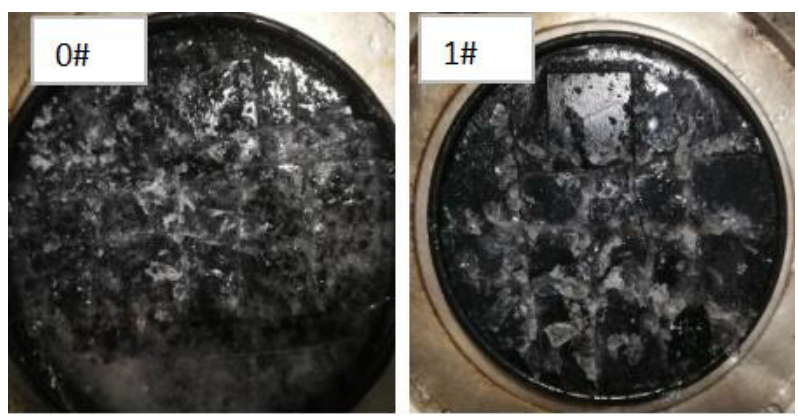

Figure 8. Detection of ice breaking effect under freezing $-10^{\circ} \mathrm{C}$. 

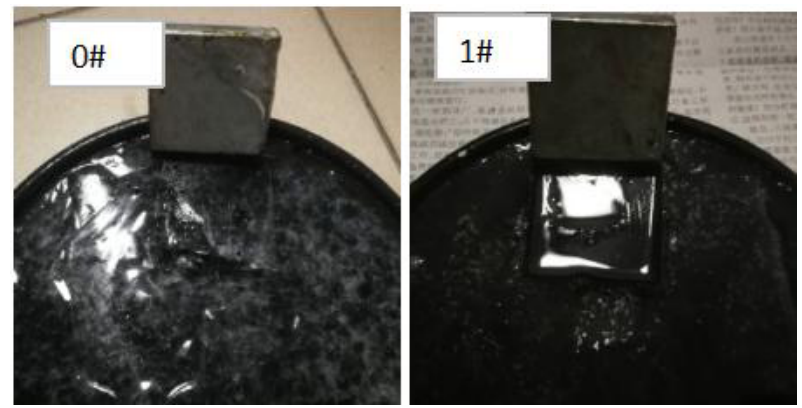

Figure 9. Freezing $-10^{\circ} \mathrm{C}$ pull-down test.

Table 2. Test data sheet of surface ice strength of test piece.

\begin{tabular}{ll}
\hline Bond strength $(\mathrm{MPa})$ & $-10^{\circ} \mathrm{C}$ \\
\hline $0 \#$ & 0.368 \\
$1 \#$ & 0 \\
\hline
\end{tabular}

As shown in figures 8 and 9. It can be clearly seen from freezing at $-10^{\circ} \mathrm{C}$ that the blank specimen has high freezing hardness and is difficult to be scratched. The ice layer and the specimen are tightly frozen together, and the drawing test data are large. The self melting ice specimen has low freezing hardness and can be easily scratched. The ice layer is not completely frozen with the specimen, and a small amount of water is not frozen in the structural depth of the specimen. Moreover, the drawing test data of self melting ice specimen is significantly lower than that of blank specimen, as shown in table 2 .

\section{Conclusion}

(1) Selecting the self melting ice modifier with weak moisture absorption and wrapping the self melting ice modifier can effectively reduce the contact area between the self melting ice modifier and water in the air, and weaken the moisture absorption capacity and slow-release effect.

(2) According to the experimental verification of mixing amount, the addition amount of self melting ice modifier is selected to $0.5 \mathrm{~kg} / \mathrm{m}^{2}$. This method not only ensures the self melting performance, but also minimizes the impact on the fine surface.

(3) The test piece at the fine surface of self melting ice and the blank test piece shall be placed at $-10^{\circ} \mathrm{C}$. Through the drawing experiment and ice rowing experiment, it is verified that the ice melting effect of the self melting fine surface is remarkable.

\section{References}

[1] Mu YL. Applied research of fine surface treatment in surface repair of asphalt pavement. Chongqing: Chongqing Jiaotong University; 2017.

[2] HOPSTOCK DZ. Minnesota taconite as a micro-wave-absorbing road aggregate material for deicing and pothole patching applications. Duluth: University of Minnesota Duluth; 2005. 
[3] MHD. Microwave-absorbing road construction and repair material. Duluth: University of Minnesota Duluth; 2003.

[4] J C O T. The Respone of asphalt concrete pavements to low temperature climatic environments. Michigan: The University of Michigan; 1992.

[5] Muthumani A, Fay L, Akin M, et al. Correlating lab and field tests for evaluation of deicing and antiicing chemicals: a review of potential approaches. Cold Regions Science and Technology, 2014 Jan; 97(4): 21-32.

[6] Ma T, Geng L, Ding XH, et al. Experimental study of deicing asphalt mixture with anti-icing additives. Construction and Building Materials, 2016 Nov; 127(2): 653-662.

[7] Hassan Y, Halima A O , Razaqpur A G, et al. Effects of runway deicers on pavement materials and mixes: comparison with road salt. Journal of Transportation Engineering, 2012 Jul; 128(4): 385-391.

[8] Hara S, Miura M, Uciumi Y. Suppression of deicing salt corrosion of weathering steel bridges by washing. Corrosion Science, 2005 Oct; 47(10): 2419-2430.

[9] Liu Z, Xing M, Chen S. Influence of the chloride-based anti-freeze filler on the properties of asphalt mixtures. Construction and Building Materials, 2014 Jan; 51(31): 133-140.

[10] Fan TT. Application study on the road performance of salt anti-freezing asphalt mixture. Hangzhou: Zhejiang Sci-tech University; 2015.

[11] Herif Y, Chirstopher Y, David F, et al. Conductive concrete overlay for bridge deck deicing: mixing proportioning, optimization and properties. ACI Materials Journal, 2000 Mar, 97(2): 172-181. 